\title{
“I pay enough taxes already!” Applying economic voting models to
}

\section{environmental referendums*}

Nicholas Bornstein, Ecole Polytechnique Fédérale de Lausanne

Philippe Thalmann, Ecole Polytechnique Fédérale de Lausanne

\footnotetext{
* Direct all correspondence to: Nicholas Bornstein, Ecole Polytechnique Fédérale de Lausanne, ENAC INTER - REME, BP Station 16, CH-1015 Lausanne; Tel. +41 2169393 93, Fax +41 2169338 40, Email: nicholas.bornstein@epfl.ch (Alternative Email as of 01 August 2008: pharaoh@vtxmail.ch). An earlier version of this paper was presented at the $29^{\text {th }}$ Annual Meeting of the International Society of Political Psychology, July 12-15, 2006, Barcelona, Spain; and at the Faculty Workshop of the Department of Political Science at the University of Geneva, November 6, 2006. We would like to thank two anonymous reviewers of this journal, Paul Gronke, Martin Rosema, Romain Lachat, Pascal Sciarini, Daniel Oesch, Marc Bühlmann and other workshop participants for their helpful suggestions and criticism. The authors gratefully acknowledge financial support from the Swiss National Science Foundation, grant 100012103517. Data used in this article is available from the Swiss Information and Data Archive Service for the Social Sciences (SIDOS) and the Swiss Federal Statistical Office. The usual disclaimer applies.
} 


\title{
“I pay enough taxes already!” Applying economic voting models to environmental referendums
}

\begin{abstract}
Objectives. Models of economic voting have rarely been applied to referendum votes. We fill this gap by testing citizens' voting behavior on environmental policy in relation to their perception of the business cycle and general orientation towards politics. Thus, the study examines the personal, institutional and economic determinants of vote choice on 36 environmental bills from 1983 to 2004 in Switzerland. Methods. We apply a logistic hierarchical model, where individual characteristics on level-1 are nested within contextual determinants situated on level-2. Results. We confirm the crucial importance of the individual-level variables education, political affinity, car ownership and urbanity. Classifying the electorate into five groups, using open-ended survey questions about respondents' reasons for approval or dismissal of the bills, allows for finer hypotheses testing. We show that the individuals' positive perception of their personal current economic conditions has a positive effect on the likelihood of supporting the proposals. In turn, we prove the negative, constraining effect of deteriorating macroeconomic conditions on approval rates. Conclusions. By applying economic voting models to referendum analyses we advance the understanding of citizens' vote choice on environmental ballots, we show the role of context and we propose an original typology of voters' general orientation towards politics.
\end{abstract}

\section{Introduction}

Analyses of votes on environmental issues remain rather scarce in scholarly research. As the issue is gaining prominence on political agendas of developed countries more attention is 
being turned to discriminating factors influencing approval or dismissal of environmental ballots. In Switzerland, which has a long record of voting on the environment and where direct-democratic instruments allow the people to vote on new laws and constitutional amendments, data is more easily to come by. Indeed, studies on environmental referendums usually hail from Switzerland and American states such as California, which know extensive direct democratic instruments. Most of the research on environmental voting was carried out in the public choice tradition which expects voters to maximize personal utility when stepping into the voting booth, even when making a choice on a public good such as the environment (Deacon and Shapiro, 1975; Fischel, 1979; Kahn and Matsusaka, 1997; Thalmann, 2004). We aim to develop a theoretical foundation of voting behavior regarding environmental projects going beyond cost benefit analysis.

Indeed, election outcomes in advanced industrialized democracies have often been explained by advancing economic arguments. However, very little attention has been paid to the impact of individuals' perceptions of economic predicaments on referendum outcomes (for an exception see Bowler and Donovan, 1998: ch. 4). Early research in voting behavior has shown that voters' choices in elections are heavily influenced by their perception of economic conditions - be it their own financial situation or that of the country (Kramer, 1971; Kinder and Kiewiet, 1981). Since referendums pertaining to environmental issues often entail a personal monetary factor and, in the view of many voters, have a considerable impact on the nation's economic performance upon approval, their study is particularly appropriate for testing economic voting models. Thus, this paper shows that negative perceptions of micro- and macro-economic conditions have a constraining effect on the probability of the support of environmental ballots. However, as we maintain, other factors going beyond cost benefit calculus matter too (cf. Bornstein and Lanz, in press). 
Switzerland practices a high level of direct democracy and is characterized as a consensus democracy. Its citizens are called up to four times a year to vote on several proposals of amendments to the Constitution or new laws which can be initiated by the people or are mandatory under the Constitution. They often bear directly or indirectly on government finances, spending and public management. For the present paper we analyze all referendums pertaining to environmental protection from 1983-2004. Not only is the policy domain rapidly gaining prominence on political agendas across the entire globe but referendums on environmental protection make up almost a fifth of all referendums voted upon in Switzerland since 1981 (Kriesi, 2005). It is thus of crucial importance to understand what shapes people's vote on environmental issues.

Finally, while voting behavior analyses usually rely on socio-structural data reflecting personal traits and preferences, we cannot neglect that a considerable portion of information is withheld. As it is, we have at our disposal a database of Swiss post-referendum surveys from 1983 to 2004, the so called VOX-data, which not only ask for citizens’ preferences and characteristics but also requires them to motivate their voting decision. Thus, we make use of Swiss citizens' stated voting motives in the survey to create a typology of the electorate which is rooted theoretically in the literature of economic voting and public choice. This allows us to put the motivation groups to the test in a sophisticated multilevel econometric model. Most voting analyses neglect the crucial impact the context exerts on individual decision-making as only few scholars have included aggregate data on a second level to augment the traditional individual-level model (Jones, Johnston, and Pattie, 1992; Steenbergen and Jones, 2002; Kriesi, 2005; Sciarini, Bornstein, and Lanz, 2007). By modeling contextual characteristics in multilevel models we are able to control for institutional and economic factors going beyond preference-based assumptions. 
Following this introduction, section 2 will give a description of the five-fold voter typology based on stated motives for approving or rejecting an environmental referendum. In section 3 we present the hypotheses, the data and discuss the distribution of the electorate into the five motivation groups. Consequently, the econometric model is introduced in section 4. Section 5 presents the estimations' results and their discussion, before we conclude the paper in section 6.

\section{A five-fold typology of the electorate}

American scholarly research on voting behavior has generally concluded that voters have great difficulties understanding ideologies or issues during political campaigns. Similarly as in the United States, skepticism remains as to the ability of the Swiss electorate to make reasoned decisions (Converse, 1964; Luskin, 1990; Christin, Hug, and Sciarini, 2002). As a way out of this cognitive ability-trap citizens are believed to reason their decision in part by relying on heuristic cues and shortcuts, i.e. to emulate the behavior of citizens disposing of greater political knowledge (Sniderman, Brody, and Tetlock, 1991; Lupia, 1994). Not only does the lack of understanding have detrimental effects on the approval of projects at ballots but voters will also follow the elite's opinion and thus make their choice dependent on the direction of the debate in the public arena (Zaller, 1992; Sciarini and Marquis, 2000; Sciarini, Bornstein, and Lanz, 2007). Finally, voters might also follow their government's recommendations when casting a vote (Kriesi, 2005) or those of political parties, which serve as a reliable and not very costly shortcut to decision-making (Downs, 1957). Following this discussion we can define the first group of our typology, namely the Cue-takers. They follow their "gut feeling” or short-cuts and cues such as voting recommendations given by the authorities or by their reference political or environmental organization. ${ }^{1}$ 
Another way for voters to address complex political choices is to rely on ideologies, i.e. a set of personal prejudgments. Even without external cues, voters in our second group, called Ideologues, are able to position a proposal relative to their prejudgments and to decide on that basis. They explain their vote with a simple slogan, void of sophisticated reasoning. Converse (1964: 216) argued similarly in his five-fold typology that ideological respondents relied on "a relatively abstract and far reaching conceptual dimension as a yardstick against which political objects ... were evaluated”. Ideologues could be in favor of any environmental policy without consideration for costs, just as, they could oppose any government intervention aiming to protect the environment without thinking about the consequences.

Much of the literature on environmental referendums was carried out in the public choice tradition, which emphasizes the role of cost benefit analyses (CBA) on individual decisionmaking (Deacon and Shapiro, 1975). Scholars contend that price and income effects explain most of the variance and that ideological considerations are negligible (Kahn and Matsusaka, 1997). Similarly, the economic voting literature stresses that citizens make a vote choice based on their perception of national or personal economic welfare. Although the latter strand of literature has been applied mainly to parliamentary and presidential elections, we extend the arguments to test how the approach fares when studying referendums. The first distinction among CBA-based decision-making must be made between "pocketbook" and "sociotropic" voters. Citizens following pocketbook considerations watch their personal financial situation closely and, upon this, reward or punish the incumbent party. $^{2}$ Sociotropes, on the other hand, make a decision based mainly on the nation's past economic performance. However, "pocketbook voting will be more likely among those citizens who see their own problems as having social or collective causes...” (Kinder and Kiewiet 1981: fn. 56). ${ }^{3}$ Sociotropes base their judgment on a rough 
evaluation of the economy-wide consequences of a proposal, as opposed to the pocketbook voters who focus on direct personal consequences. Following this argument, sociotropic voting can even be led completely by self-interest when a voter takes the nation's health as an indicator of how her personal welfare is attributable to the incumbent party, but she could also be concerned by other people's welfare. We reserve therefore the name of Selfish voters for the third group of the electorate, which compares the costs and benefits of a proposal mainly for itself emphasizing for instance tax hikes, reduced mobility or a cleaner environment.

Among the sociotropes we differentiate between myopic and future-oriented voters. Obviously, current economic conditions are more easily perceptible by the average voter than forecasting the future effects a politician's policy would have on her personal welfare (Fiorina, 1981; Erikson, 1989). Thus, we expect the fourth category of voters, the Myopic voters, to compare the current costs and benefits of a proposal from a sociotropic point of view, emphasizing for instance impacts on employment, budget, or international competitiveness. However, MacKuen, Erikson, and Stimson (1992) argue that the electorate is anticipating and foresighted rather than myopic (see also Lewis-Beck, 1988: 118-125). Indeed, environmental issues encourage prospective sociotropic voting as they are generally linked directly or indirectly to questions of sustainability and the security of our future. Extending the argument somewhat, we contend that these citizens do not only think of national future economic prospects, i.e. economic growth, but also about general questions linked to the preservation of resources and the future of our natural habitat when making a choice. Our last group therefore, the Anticipatory voters, is believed to compare the future costs and benefits of a proposal from a sociotropic point of view too, but emphasizing longterm impacts of government policy, i.e. issues linked to sustainability, land use changes or the impact of a proposal on future national economic development. 
Table 1 provides an overview of the five groups, their theoretical underpinnings, and some examples of responses given. Note that in each group voters can decide to approve or reject an environmental proposal depending on how they assess its consequences along their priorities and on how they weigh those priorities. Therefore, all groups comprise yes- and no-voters. For that reason, attributing voters to a group will not determine her vote but only indicate what aspects of a proposal she might emphasize. More control variables and such pertaining to the context-level are needed to explain votes.

\section{TABLE 1 ABOUT HERE}

In the following, we discuss some of the control and context variables used in our hierarchical regression models. Early studies in the 1970s, conducted with aggregate voting data and post referendum survey data in the United States, showed that environmental projects at ballots were strongly disapproved by voters with conservative political views (Deacon and Shapiro, 1975; van Liere and Dunlap, 1980) but embraced by those with higher education (Fischel, 1979). Those results were confirmed by later empirical studies (Kahn and Matsusaka, 1997; Thalmann, 2004; Bornstein and Lanz, in press). One might expect younger voters to be more supportive of environmental ballots because they are more concerned by long-term environmental changes or because they share post-materialist values, but these assumptions were refuted by empirical studies in the Swiss context (Sciarini, Bornstein, and Lanz, 2007). Nevertheless, we will control whether respondents giving a voting motivation in terms of prospective impacts decide differently when it comes to votes on nuclear power. We believe these questions to be particularly salient to anticipatory voters since they are hard to grasp in terms of a single lifespan (consider the half-life of nuclear waste) and call upon post-materialist ideals.

Urban voters might be more favorable to environmental policy because they are more exposed to nuisances and they value the leisure value of open spaces more than its 
productive value. On the other hand, caution must be exerted because urbanity is correlated with other voter characteristics such as more leftist political preferences and higher education and income (Salka, 2001). Finally, a variable pertaining to private transport shall control for utilitarian arguments. We know that people possessing one or several cars are less likely to accept environmental proposals (Thalmann, 2004), be it because they appreciate mobility more or because of the associated leisure. A survey among citizens not possessing a car - around 25\% of all households in Switzerland - either made a considerate choice against private transportation and for the environment (about one third), adapted to exogenous factors (e.g. insufficient financial resources, prevalence of public transport in their urban area, health-related reasons; about one fifth), or are rather ambivalent with respect to the reasons of not possessing a car (Müller and Romann, 1999).

Furthermore, to be able to provide a general measure of economic conditions close to the voters' interests, we use the change in consumption climate from the preceding quarter. For a narrower measure of economic conditions related to environmental policy, we use the price of gasoline on a year-to-year basis. We expect both predictors to have a negative impact, ceteribus paribus, on vote choice when their values are worsening, i.e. when confidence falls or the gas price rises. Finally, as mentioned above, earlier research showed that the ballot's design, such as its comprehensibility and the elite's position on a specific proposal both have a significant impact on choice behavior (cf. Zaller, 1992).

\section{Hypotheses and data}

First we test assumptions on personal determinants of environmental voting and on the motivation groups in a single-level model. Next we add economic and institutional predictors on a second level. This will allow for more detailed hypotheses testing, namely the possibility to test cross-level interactions. 
H1 - Motivation groups (Ideologues as reference category)

1a. When other personal factors are taken into account, Selfish and Myopic voters will vote significantly more against the environmental proposals. $1 b$. On the other hand, Anticipatory voters will be more favorable. 1c. Cue-takers will vote in line with their government, i.e. rather against the proposals, of which most were introduced by popular initiative.

H2 - Context variables significantly improve the model's ability to predict individual votes over time.

2a. A positive change in consumption climate will increase the probability of approval because a better position in the economic business cycle promotes voters' willingness to pay for the environment. The contrary applies for the measure of general economic conditions: higher gas prices decrease ballot support. $2 b$. The probability of approval of proposals that are unanimously supported by the Swiss elites will be higher.

H3 - Interaction effects: the same context variables are not equally important for all motivation groups.

3a. Selfish voters making their choice dependent on the change in the consumption climate will be incited to vote more strongly in favor of the environmental proposals as the consumption climate improves. $3 b$. When the Myopic voters take into account general economic conditions, their rejection of the projects will be offset when gas prices are lower. 3c. Anticipatory voters are more likely to approve proposals restricting nuclear power than the other groups. 3d. Cue-takers will vote even more strongly against all environmental proposals when the elites are divided.

\section{The VOX surveys}

Since 1981 a representative telephone survey has been conducted within three to four weeks after each national vote (hereafter VOX survey). Each survey interviews 
approximately 1,000 adults following a uniform blueprint augmented by questions specific to each vote. For this study, we pooled the data from 19 VOX surveys bearing on 36 environment-related policy proposals put to vote over the last 21 years (a complete list of all votes is available from the authors upon request or can be consulted at http://www.admin.ch/ch/f//pore/va/vab_2_2_4_1.html). The proposals were voted upon during only 19 weekends, as it is usual in Switzerland to bundle referendums. For most proposals, voting yes was voting in favor of some environmental improvement; the two objects for which that was not the case were recoded accordingly.

For the present study, there were initially a total of 36,514 observations dispersed over 38 votes. ${ }^{4}$ Eliminating respondents who did not participate in the popular vote and those who did not answer all personal questions reduces the sample to 18,815 observations. The sample is further reduced to 14,989 observations by missing answers to the motivation question and by ambiguous answers that did not allow allocating a respondent to any group. After inspection of descriptive data, we found that two of our votes in 1984 were badly biased with approval rates of around 90\%. Unreliable data in the early VOX surveys is known to be an often encountered problem, especially with respect to the motivation questions. Thus, we decided to delete these two votes which reduced the sample size to 14,633 respondents distributed over 36 votes.

The question in the VOX survey about voters' motives for casting a ballot in favor or against the proposal of the day has hardly been used in past scientific research. It is the only open question in the survey, which might explain some reluctance towards its exploitation. ${ }^{5}$ We do not dispose of the answers themselves but their recoding by the survey organizers, often just a word or two, which prevents us from making all the distinctions we might think of. The original question is as follows: "What is the main reason for which you approved/rejected the proposal?” Many voters cannot be allocated to any group because they 
did not answer the motivation question or their answer was coded in an ambiguous way. ${ }^{6}$ Additionally, attributing voters to groups was a difficult task as some proposals pursued very narrow and issue-specific goals.

\section{Distribution of voters into the five-fold typology}

Table 2 shows how the voters were allocated to the motivation groups outlined above. The largest group is that of Myopic voters with 30\% of the electorate, closely followed by the Ideologues (28\%) and the Anticipatory voters (27\%). The Selfish voters represent only $11 \%$ of the sample, but that might be related to our a priori that voters concerned by high prices or employment loss worry not primarily for themselves and are therefore classified as Myopic voters. Anyway, adding them to the motivation groups of Myopic and Anticipatory voters yields nearly $70 \%$ of the electorate who based its vote on considerations of costs and benefits of the proposals.

Comparing voters who supported and opposed the environmental proposals shows clearly that more supporters are Anticipatory voters and more opponents are Selfish voters. The other groups are about equally distributed. Next we checked the personal composition of the groups in terms of gender, education, linguistic region, urban/rural location and political preferences. No category was clearly over-represented in any of the groups, except that voters with university education were less often allocated to the Selfish group (7\% of them against $13 \%$ of the voters with minimal education) and more often to the Ideology group (31\% vs. 24\%). This increases the information value of the grouping.

\section{TABLE 2 ABOUT HERE}

Only education makes a small difference among those who did not answer the motivation question or gave an answer that the interviewers could not interpret: $6 \%$ of the voters with university education did not answer the motivation question and $14 \%$ gave an 
undeterminable motivation, against $11 \%$ in each group at the other extreme, that of voters with only compulsory school education. Leaving out respondents whose motivation answer cannot be used from the sample for future analysis should not bias our results.

Finally, regarding political preferences, voters who place themselves on the left belong more often to the Anticipatory voters and the Ideologues (30\% each) than voters on the right (24\% and 27\% respectively). Left partisans seem to be the ones most concerned by future environmental degradation. Right partisans are a little more often allocated to the Myopic (33\%) and the Selfish voters (12\%) than voters on the left (28\% and 8\% resp.); hence, leftist voters seem to focus a little less on their own well-being than voters on the right when deciding on environmental projects. Voters in the centre and non-partisans are in between.

\section{The econometric model}

We use a logistic multilevel model where the dependent binary variable is approval or rejection of environmental proposals and where individual characteristics on level-1 are nested within contextual determinants on level-2. Where necessary, we re-coded the dependent variable so that the vote always represents a choice in favor of the environment. Most individual-level explanatory variables in the VOX database were contrast coded (dummy variables) with 0 being the reference category. This is the case for the variables “male” ( $0=$ female), "urban” ( $0=$ living in rural area), "car” ( $0=$ owns no car) and "latin" (0=living in German-speaking part of the country). Education is an ordinal variable scaled from 0 to 3 for compulsory school (reference category), apprenticeship (“apprentice”), high school diploma (“maturity”), and university degree ("university”). The reference category for the age-predictor is the group 18 to 29 years, with the other groups being 30-44, 45-59, and 60+. 
The partisanship variable was based on two questions regarding party identification and self-positioning on a left-right scale. The multiplicity of political parties in Switzerland is reduced to three families: the conservative right (Swiss People’s Party, Swiss Democrats and other parties of the radical right), the moderate right (Christian Democrats, Radicals, Liberals and other small parties), and the left (Social Democrats, Greens, Workers Party and other small left parties). ${ }^{7}$ Voters who do not identify with a party but position themselves clearly on one side of the left-right scale are added to the corresponding category. We select the non-partisans as the reference category.

The change in consumption climate from the preceding quarter is indicated by " $\Delta C C$ "; the indicator's values were attributed to each voting weekend. It is based on the Swiss Consumer Confidence Survey held every three months in Switzerland among a representative sample of 1,000 citizens who are asked a total of nine questions about their consumption behavior in the near future and past (data from SECO/State Secretariat for Economic Affairs). ${ }^{8}$ The price of gasoline is measured as a yearly average and deflated by the consumer price index ("gas price”). Both variables were standardized with mean 0 and standard deviation of 1 to facilitate comparison. ${ }^{9}$

The difficulty of decision-making on a specific proposal is measured through a variable where respondents were asked whether they had found it rather hard or easy to make up their mind regarding the proposals on the ballot (“difficult”). The elite's position on the proposals is measured by a dummy variable which defines votes supported unanimously (“consensus”). This was never the case for popular initiatives since in general they refer to claims by political outsiders or movements which are deemed too extreme by the established actors. $^{10}$ In the time frame of this research only six out of 81 popular initiatives were accepted, three of those being included in our data set. As aforementioned, we also included a dummy variable for all votes pertaining to nuclear power (“nuclear”). 
Hierarchical models have been used only rarely to examine the impact of geographical and other contextual characteristics on individuals' voting choices (Jones, Johnston, and Pattie, 1992; Bühlmann, 2006; Sciarini, Bornstein, and Lanz, 2007). For the present purpose, a two-level logistic random intercept model is chosen. The model suits our hypotheses best as we can test for variances on the individual and contextual level since voters' choices are influenced by their personal characteristics as well as by the context in which they are embedded (Steenbergen and Jones, 2002). It means that we estimate an intercept that is constant for all voters in a particular referendum but randomly variable across the 36 referendums.

As the dependent variable in our multilevel model is discrete, either approval or refusal of environmental protection measures, we apply a logistic hierarchical regression. The model has the following structure: the lower-level consists of the individuals who are nested within the ballot proposals on level-2. The formal representation of the model follows closely Snijders and Boskers (1999: 207-226). $\mathrm{Y}_{\mathrm{ij}}$ denotes support or refusal of an environmental proposal by individual $i$ on level- 1 nested in level- 2 context $j$. Predictor variables are denoted by $X_{1}$ to $X_{r}$ taking values $x_{h i j}(h=1, \ldots, r)$. The logistic random intercept model expresses the logit of $P_{i j}$, the probability of supporting the proposal, as a linear function of the explanatory variables and a random deviation $U_{0 j}$ that depends on level-2 context

$$
\operatorname{logit}\left(P_{i j}\right)=\gamma_{0}+\sum_{h=1}^{r} \gamma_{h} x_{h i j}+U_{0 j}
$$

The random deviations $U_{0 j}$ are assumed to follow a Normal distribution with zero mean and a variance of $\tau_{0}^{2}$.

The hierarchical logistic regression can also be formulated as a threshold model where the dichotomous outcome $\mathrm{Y}$ is then conceived as the result of an underlying non-observed 
continuous variable. The underlying variable is denoted by $\bar{Y}$. We state that $Y$ is 1 , if $\bar{Y}$ is larger than the threshold, and 0, if it is less than the threshold. As we are working with unobserved entities let the threshold be 0 . Thus, for the unobserved variable $\bar{Y}$ we have a random intercept model of the following form

$$
\bar{Y}_{i j}=\gamma_{0}+\sum_{h=1}^{r} \gamma_{h} x_{h i j}+U_{0 j}+R_{i j}
$$

where the cumulative distribution function of the level-1 residual $R_{i j}$ is a logistic function with mean 0 and variance of $\pi^{2} / 3 \approx 3.29$. By assuming that $R_{i j}$ has this distribution, (2) is equivalent to (1). We define a threshold model so as to be able to calculate the proportion of explained variance using McKelvey and Zavoina’s $R_{M Z}^{2}$.

All models were estimated with the multilevel software package MLwiN using the Reweighted Iterative Generalised Least Squares (RIGLS) algorithm, $2^{\text {nd }}$ order penalized quasi-likelihood (PQL) (Rasbash et al., 1993).

\section{Discussion of the results}

\section{Single-level model}

The results for the single-level model confirm our hypotheses about the positive effects of higher education, urbanity and left partisanship. As can be seen from table 3, the direction of the signs and the statistical significance of the coefficients confirm our assumptions. The left and green partisans and those having attended university vote more strongly in favor of the proposals. The positive effect for women implies that gender does have an impact on green voting. We suspect that this could be linked to motherhood questions, whereby women might be more sensitive to of the consequences of resource depletion for our descendants. Urban dwellers, too, have a higher probability of accepting the ballot propositions whereas those possessing one (or several) private car(s) have a smaller probability of voting yes. The 
predictor measuring people's difficulty when making a choice is not statistically significant. In line with earlier studies, the age coefficients have a negative sign, suggesting that the older voters are less supportive of environmental policy (Thalmann, 2004; Bornstein and Lanz, in press). Furthermore, the probability of support for environmental policy in the French- and Italian-speaking regions is lower than in the German part of the country, an effect frequently observed in Swiss referendums (Kriesi, 1999).

\section{TABLE 3 ABOUT HERE}

The single-level model in table 3 also includes the motivation groups, with the group of the Ideologues serving as the reference category. We observe that, compared to the Ideologues, the probability that Selfish voters and Cue-takers approve environmental proposals is weaker. The two groups representing sociotropic voting confirm our expectations partly: while voters reasoning in short-term cost-benefit terms are less likely to approve the proposals, the coefficient does not attain statistical significance for the Anticipatory voters. We will comment in more detail on these effects when discussing the full model below. However, it becomes clear that hypothesis 1 is not fully confirmed.

Adding the motivation group indicator into the vote equations is mainly designed to better understand the consequences of belonging to those groups rather than to raise the predictive power of the model. Indeed, in separate tests not shown here, we found that the proportion of explained variance was only minimally smaller without the groups. There are only $32 \%$ of voters in favor of the environment in the Selfish group against $57 \%$ in the reference group of the Ideologues and 58\% in the group of the Anticipatory voters. Thus, the clearly significant and very large negative coefficient for Selfish means that, when their personal characteristics are taken into account, voters who weigh the benefits and costs of environmental proposals for themselves tend to reject them more frequently than the Ideologues. The same is true for the Myopic voters, but in lesser magnitude. The 
Anticipatory voters then react more positively to the proposals, although the difference is not statistically significant, a finding which is in line with the high percentage of yes-voters in that group. However, belonging to the Cue-takers leads to voting more often against the environment, which is most likely due to the lop-sided elite configuration for a majority of the ballot propositions: all initiatives and three referendums (a total of 24 out of the 36 proposals under study) faced opposition by the national government, major employers' organizations and the three liberal-conservative government parties.

\section{Two-level model}

Adding level-2 contextual explanatory variables allows testing our hypotheses on the economic and institutional effects on vote choice. The variables' coefficients confirm our $a$ priories. The results are displayed in table 3 as well. While the coefficients of the individual determinants hardly change, we note some mixed effects for the institutional and economic predictors.

First, we note that only the coefficient for the oldest voters attains statistical significance and is negative, indicating that when contextual effects of the vote are accounted for, young and middle-aged voters are influenced less by their age. Furthermore, more complex proposals diminish the probability of voter approval, thus confirming earlier findings that projects which were not well understood by the electorate faced a tough challenge at ballots (Zaller, 1992; Sciarini, Bornstein, and Lanz, 2007). Furthermore, we note a positive effect for ballot propositions which gained unanimous support from the Swiss elites. Inversely, this implies that the left, which in environmental referendums always opposes the established parties and organizations in the center and on the right, has great troubles passing green ballots if it does not receive support from the bourgeois parties, organized business and employers’ organizations. 
The two measures of current economic conditions, the change in consumption climate and the deflated gasoline price, show mixed effects: the effect of a higher gas price is clearcut, namely it lowers the probability of approval. Our expectation that citizens are inclined to vote in favor of the projects when they perceive the change in the consumption climate positively is also confirmed. A caveat applies though: for the Selfish voters this is not the case (see below). Thus, all hypotheses pertaining to the context level are confirmed. It remains to see how the determinants fare when put in interaction with the separate motivation groups.

As mentioned above, group membership must be regarded less as an element to increase the predictive power of the model, but rather in terms of discriminating what sort of considerations play a role for the voters' choice after controlling for socio-structural characteristics. We note that the coefficients from one equation to the next remain robust but that there is improvement in that the coefficient for the Anticipatory voters is now statistically significant. Selfish voters, as expected in our hypotheses, have a greater probability of rejecting the proposals. This is also true for the Anticipatory voters; in accordance with our hypothesis, voters who are farsighted when making a decision will rather approve of the environmental proposals. This effect is statistically significant at the 1\%-level as are all effects for the motivation groups in the full model. Finally, voters following cues rather vote against the proposals, thus following the majority of the elites' voting recommendations in our case. Thus, expectations outlined in hypothesis 1 can be confirmed for the full model whereas for the single-level model this is not the case.

First, we test the pocketbook voting hypothesis by checking how the Selfish voters' choice is influenced by the recent change in the consumption climate: the group's already impressively lower probability of accepting environmental measures is further reduced. Thus, voters deciding about a proposal on the basis of its impact on their personal financial 
situation are even more likely to reject environmental proposals in times of improving consumer prospects. This goes clearly against our assumptions of the beneficial effect of the change in the consumption climate. We might want to interpret this effect as a preponderance of material values, i.e. the increased availability of consumer goods when pocketbooks are full over immaterial environmental values. This finding is supported by Halbheer, Niggli, and Schmutzler (2006) who contend that voters, in their role as consumers, reject environmental proposals when it entails a restriction of their consumer sovereignty.

Next, we test how Myopic voters react to changing gas prices. The interaction effect does not attain statistical significance suggesting that the burden of paying more for gas is equally constraining to all voters. This finding has direct repercussions on the above result, namely that voters react very sensitively to any kind of additional financial burden placed upon them (cf. Deacon and Shapiro, 1975). Thus self-interest seems to prevail for the pocketbook voters and macro-economic changes affect the entire electorate.

Closely linked to the post-materialist hypothesis, the nuclear-dummy stands for the four initiatives asking for an exit from nuclear power (two in 1990; two in 2003). In each year one of the initiatives asked for a total exit while the second, voted upon on the same weekend, asked for a ten-year ban on further construction of nuclear power plants. The moratorium was accepted in 1990 but not in 2003, which is most likely due to the catastrophe in Chernobyl in 1986. We expect Anticipatory voters to be particularly sensitive to the preservation of a sound environment for their descendants and to be concerned about nuclear power and waste storage; the positive sign of the interaction effect confirms our expectations. Hence, while this group is more likely to approve anti-nuclear initiatives this does not hold true for the other groups as the coefficient for "nuclear" is statistically insignificant. 
Lastly, we test whether voters who indicated that they follow the government's or their family's and friends' advice are particularly sensitive to the elite's opinion. It appears that the Cue-takers' support decreases in mainstream situations, i.e. when elites back a proposal unanimously. This result is surprising. We are led to believe that the Swiss system, grounded in consociationalism, i.e. guaranteed group representation, raises the possibility of a protest vote in times when the elites tend towards a consensus-oriented position. In other words, these voters might be dissatisfied with the bargaining in parliament which led to a lackluster compromise and therefore refrain from supporting this type of coalition. Thus, in conclusion we must reject partly hypothesis 3 since Selfish voters did not react favorably to the increase in their consumer prospects nor did the Myopic voters react differently to the proposals compared to the rest of the electorate.

\section{Conclusion}

Notwithstanding a great number of studies focusing on the relationship between election outcomes and economic conditions, evidence on the impact of evaluations of the economy on referendum votes is still scarce. To fill this gap we tested how different voting models fare when put to the test on environmental referendums. We translated different models of individual decision-making into a typology of voters and allocated voters to the five groups based on the main reason they gave for approving or rejecting an environmental proposal. This approach has proven fruitful, not so much in increasing the predictive power of the model than in better understanding why context variables affect votes as they do. Moreover, we confirm that economic voting models can be applied very well to referendums and that they are highly beneficial to the understanding of environmental voting behavior.

These results have some implications for environmental policymaking in developed countries. They show that policymakers ought to take into account people's concerns about 
the economy or their personal financial situation when presenting proposals to the public. As environmental proposals may well be cost-intensive and require heavy state intervention, new instruments such as emissions trading, or incentive taxes which provide full redistribution of revenues, must be pursued. We argue that these instruments - despite some troubling counter-evidence from Switzerland (Bornstein, 2007; Thalmann and Baranzini, 2008) - may well be better suited to receive public support if major interest organizations and parties choose to support them, too. However, it does not suffice to work on the design of these proposals only; our results also seem to imply that it is conducive to the acceptability of the bills when people feel confident financially speaking. While it is hard to time the bills accordingly and rather launch them in times of economic upswing, they do stand a bigger change of being accepted when the global and national economy makes people feel like they can spare some of their taxes' money on such post-material issues as the protection of our natural habitat and resources.

\section{References}

Bornstein, Nicholas. 2007. "Alliance Formation in the Pre-Parliamentary Phase in Switzerland: Towards a Re-Configuration of the Environmental Policy Space?” mimeo. Bornstein, Nicholas and Bruno Lanz. in press. Price or ideology? Evidence from Swiss referendums. Ecological Economics.

Bowler, Shaun and Todd Donovan. 1998. Demanding Choices: Opinion, Voting, and Direct Democracy. Ann Arbor: University of Michigan Press.

Bühlmann, Marc. 2006. Politische Partizipation im kommunalen Kontext. Der Einfluss lokaler Kontexteigenschaften auf individuelles politisches Partizipationsverhalten. Berner Studien zur Politikwissenschaft Band 13. Bern: Haupt Verlag. 
Christin, Thomas, Simon Hug, and Pascal Sciarini. 2002. Interests and information in referendum voting: An analysis of Swiss voters. European Journal of Political Research 41(6):759-776.

Conover, Pamela Johnston and Stanley Feldman. 1986. "Emotional Reactions to the Economy: I'm Mad as Hell and I'm Not Going to Take It Anymore.” American Journal of Political Science 30:50-78.

Converse, Philip E. 1964. “The Nature of Belief Systems in Mass Publics.” Pp. 206-261 in David E. Apter, ed., Ideology and Discontent. New York: Free Press.

Deacon, Robert and Perry Shapiro. 1975. "Private Preference for Collective Goods Revealed through Voting on Referenda.” American Economic Review 65(5):943-955.

Downs, Anthony. 1957. An Economic Theory of Democracy. New York: Harper and Row.

Erikson, Robert S. 1989. "Economic Conditions and the Presidential Vote.” American Political Science Review 83:567-573. 20

Fiorina, Morris P. 1981. Retrospective Voting in American National Elections. New Haven, CT: Yale University Press.

Fischel, William A. 1979. "Determinants of Voting on Environmental Quality: A Study of a New Hampshire Pulp Mill Referendum.” Journal of Environmental Economics and Management 6:107-118.

Halbheer, Daniel, Sarah Niggli and Armin Schmutzler. 2006. "What Does it Take to Sell Environmental Policy? An Empirical Analysis of Referendum Data.” Environmental and Resource Economics 33:441-462.

Jones, Kelvyn, Ronald J. Johnston and Charles J. Pattie. 1992. "People, Places and Regions: Exploring the Use of Multi-Level Modelling in the Analysis of Electoral Data.” British Journal of Political Science 22(3):343-380. 
Kahn, Matthew E. and John G. Matsusaka. 1997. “Demand for Environmental Goods: Evidence from Voting Patterns on California Initiatives.” Journal of Law and Economics 40:137-173.

Kinder, Donald R. and D. Roderick Kiewiet. 1981. "Sociotropic Politics: The American Case.” British Journal of Political Science 11:129-161.

Kinder, Donald R., Gordon S. Adams and Paul W. Gronke. 1989. "Economics and Politics in the 1984 American Presidential Election.” American Journal of Political Science 33(2):491-515.

Kramer, Gerald H. 1971. "Short-Term Fluctuations in U.S. Voting Behavior, 18961964.”American Political Science Review 65:131-143.

Kriesi, Hanspeter. 1999. "Opinion Formation and Change. The case of the Swiss policy against air pollution caused by cars.” Unpublished manuscript, University of Geneva.

Kriesi, Hanspeter. 2005. Direct democratic choice. The Swiss experience. Lanham, MD: Lexington Books.

Lewis-Beck, Michael S. 1988. Economics and Elections. The Major Western Democracies. Ann Arbor: University of Michigan Press.

Lupia, Arthur. 1994. "Shortcuts versus Encyclopedias: Information and Voting Behavior in California Insurance Reform Elections.” American Political Science Review 88(1):6376.

Luskin, Robert C. 1990. “Explaining Political Sophistication.” Political Behavior 12(4):331-361.

MacKuen, Michael, Robert Erikson and James Stimson. 1992. "Peasants or Bankers? The American Electorate and the U.S. Economy.” American Political Science Review 86:597-611. 
Marquis, Lionel. 2004. “The Priming of Referendum Votes.” EPERN Working Paper no. 17. Sussex European Institute.

Müller, Hannes and F. Romann. 1999. Autofreie Haushalte: Ihre Mobilität und die Folgen für Verkehrsplanung und Verkehrspolitik. Bern: Programmleitung NFP 41.

Rasbash, Jon, Fiona Steele, William Browne, and Bob Prosser. 2004. A User's Guide to MLwiN, Version 2.0. University of London: Institute of Education. Centre for Multilevel Modelling.

Salka, William M. 2001. "Urban-rural conflict over environmental policy in the western United States.” American Review of Public Administration 31(1):33-48.

Sanders, David. 1991. “Government Popularity and the Next General Election.” Political Quarterly 62:235-261.

Sciarini, Pascal. 2006. “Le processus législatif.” Pp. 491-525 in Ulrich Klöti, Peter Knoepfel, Hanspeter Kriesi, Wolf Linder, Yannis Papadopoulos, and Pascal Sciarini, eds., Handbuch der Schweizer Politik. $4^{\text {th }}$ ed., Zurich: Verlag Neue Zürcher Zeitung.

Sciarini, Pascal and Lionel Marquis. 2000. “Opinion Publique et politique extérieure: le cas des votations populaires en Suisse.” International Political Science Review 21:149-171.

Sciarini, Pascal, Nicholas Bornstein and Bruno Lanz. 2007. "The determinants of voting choices on environmental issues: A two-level analysis.” Pp. 234-266 in C. H. de Vreese, ed., The dynamics of referendum campaigns. An international perspective. London: Palgrave Macmillan.

Sniderman, Paul M., Richard A. Brody and Philip E. Tetlock. 1991. Reasoning and Choice. Explorations in Political Psychology. Cambridge: Cambridge University Press.

Snijders, Tom and Roel Bosker. 1999. Multilevel Analysis. An introduction to basic and advanced multilevel modeling. London, Thousand Oaks, New Delhi: Sage Publications. 
Steenbergen, Marco R. and Bradford S. Jones. 2002. “Modeling Multilevel Data Structures.” American Journal of Political Science 46(1):218-237.

Thalmann, Philippe. 2004. “The public acceptance of green taxes: 2 million voters express their opinion.” Public Choice 119(1-2):179-217.

Thalmann, Philippe and Andrea Baranzini. 2008. "Gradual introduction of coercive instruments in climate policy.” Pp. 53-74 in N. Chalifour, J. Milne, H. Ashiabor, K. Deketelaere, and L. Kreiser, eds., Critical Issues in Environmental Taxation. International and Comparative Perspectives. Volume V, Oxford: Oxford University Press.

van Liere, Kent D. and Riley E. Dunlap. 1980. “The Social Bases of Environmental Concern: A Review of Hypotheses, Explanations and Empirical Evidence.” Public Opinion Quarterly 44(2):181-197.

Zaller, John R. 1992. The Nature and Origins of Mass Opinion. Cambridge: Cambridge University Press. 
Table 1: Description of voter typology

\section{Name}

Cue-takers

Selfish voters

\section{Characteristics}

Shortcuts to decision making; heuristic cues; imitation of better-informed citizens; follow party’s or

government's vote recommendation

Simplistic and/or moral reasoning with ideological

backdrop; usage of slogans; very pronounced pro- or

contra-position: no concern for costs of proposals with

regard to national economic conditions or public sector

budget

Pocketbook voters; concerns for personal economic

prospects and financial situation; personal cost-benefit

analysis: prevalence of self-interest

\section{Examples of responses}

I followed family’s advice; cast my vote accordingly to the Federal Council; used my preferred party’s position as help; recommendation of friends/others I am for the environment; important to protect the Alps; too bureaucratic; polluter-pays-principle; Confederation should stop spending

I pay enough taxes already; proposal goes too far; less congestion; modest financial contribution; personally harmed; I am for cost-transparency 
Myopic voters

Sociotropic voters; compare costs and benefits of proposals for a short time frame with regards to national economic condition; past economic experiences are decisive for vote

Anticipatory voters

Prospective sociotropic voters; evaluate consequences

of proposal on future living conditions; immediate and long-term economic future crucial for choice
Proposal is harmful to economic competitiveness;

Confederation needs more money; proposal could endanger job security; no incentive to tourism; unequal distribution of costs on society

I am concerned about the future/depletion of resources; concern about economic growth; promote renewable energy vs. renewables are not yet technologically ready; leave intact environment to descendants; we need more roads to cope with ever-increasing traffic 
Table 2: Distribution of respondents according to voter typology in absolute numbers and percentages, according to vote decision

$\begin{array}{llll} & \text { Yes } & \text { No } & \text { Total } \\ \text { Ideologues } & 2,314 & 1,753 & 4,067 \\ \text { Selfish voters } & 511 & 1,088 & 1,599 \\ \text { Myopic voters } & 2,269 & 2,133 & 4,429 \\ \text { Anticipatory voters } & 2,304 & 1,638 & 3,942 \\ \text { Cue-takers } & 248 & 348 & 596 \\ \text { Total } & \mathbf{7 , 6 7 3} & \mathbf{6 , 9 6 0} & \mathbf{1 4 , 6 3 3}\end{array}$

$\begin{array}{llll} & \text { Yes } & \text { No } & \text { Total } \\ \text { Ideologues } & 30.2 \% & 25.2 \% & 27.8 \% \\ \text { Selfish voters } & 6.7 \% & 15.6 \% & 10.9 \% \\ \text { Myopic voters } & 29.9 \% & 30.6 \% & 30.3 \% \\ \text { Anticipatory voters } & 30.0 \% & 23.5 \% & 26.9 \% \\ \text { Cue-takers } & 3.2 \% & 5.0 \% & 4.1 \% \\ \text { Total } & \mathbf{1 0 0} \% & \mathbf{1 0 0} \% & \mathbf{1 0 0 \%}\end{array}$


Table 3: Support for environmental proposals at Swiss ballots; hierarchical logistic regression, RIGLS $2^{\text {nd }}$ order PQL, $\mathrm{N}=14,633$

\begin{tabular}{|c|c|c|c|}
\hline Level-1 & Level-2 & $\begin{array}{l}\text { Single-level model } \\
\text { Coefficient (s.e.) }\end{array}$ & $\begin{array}{l}\text { Two-level model } \\
\text { Coefficient (s.e.) }\end{array}$ \\
\hline Constant & & $0.751 * *(0.090)$ & $0.066(0.168)$ \\
\hline Age: $30-44$ & & $-0.098 *(0.058)$ & $-0.039(0.063)$ \\
\hline Age: $45-59$ & & $-0.128 *(0.059)$ & $-0.105(0.065)$ \\
\hline Age: $60+$ & & $-0.196 * *(0.060)$ & $-0.123^{*}(0.067)$ \\
\hline Apprentice & & $0.161 * *(0.055)$ & $0.152 * *(0.060)$ \\
\hline Maturity & & $0.301 * *(0.062)$ & $0.310 * *(0.069)$ \\
\hline University & & $0.431 * *(0.076)$ & $0.560 * *(0.086)$ \\
\hline Male & & $-0.161 * *(0.037)$ & $-0.239 * *(0.040)$ \\
\hline Urban & & $0.080 *(0.037)$ & $0.132 * *(0.041)$ \\
\hline Latin & & $-0.297 * *(0.043)$ & $-0.255^{* *}(0.047)$ \\
\hline Left & & $0.905 * *(0.047)$ & $1.065 * *(0.053)$ \\
\hline Moderate & & $-0.151 * *(0.045)$ & $-0.188 * *(0.050)$ \\
\hline Conservative & & $-0.657 * *(0.064)$ & $-0.691 * *(0.071)$ \\
\hline Difficult & & $-0.042(0.041)$ & $-0.128 * *(0.046)$ \\
\hline Car & & $-0.718 * *(0.050)$ & $-0.768 * *(0.055)$ \\
\hline Selfish & & $-0.942 * *(0.065)$ & $-1.051 * *(0.078)$ \\
\hline HAN & & $-0.157 * *(0.046)$ & $-0.288 * *(0.057)$ \\
\hline Anticipatory & & $0.055(0.048)$ & $0.297 * *(0.066)$ \\
\hline \multirow[t]{9}{*}{ Cues } & \multirow{2}{*}{\multicolumn{2}{|c|}{$-0.602 * *(0.093)$}} & $-0.492 * *(0.130)$ \\
\hline & & & $0.278 * *(0.112)$ \\
\hline & \multicolumn{2}{|l|}{ Gas price } & $-0.236 * *(0.095)$ \\
\hline & \multicolumn{2}{|l|}{ Nuclear } & $0.348(0.369)$ \\
\hline & \multicolumn{2}{|l|}{ Consensus } & $1.476 * *(0.212)$ \\
\hline & \multicolumn{2}{|l|}{ Selfish* $\Delta$ CC } & $-1.217 * *(0.066)$ \\
\hline & \multicolumn{2}{|l|}{ HAN*gas price } & $0.065(0.048)$ \\
\hline & \multicolumn{2}{|l|}{ Anticipatory*nuclear } & $0.855^{* *}(0.160)$ \\
\hline & \multicolumn{2}{|l|}{ Cues*consensus } & $-0.432 * *(0.203)$ \\
\hline \multicolumn{3}{|l|}{$\operatorname{var}\left(U_{0 j}\right)$} & $0.314^{* *}(0.077)$ \\
\hline \multicolumn{2}{|c|}{ corr. pred. (cut value at 0.5 ) } & $64 \%$ & $69 \%$ \\
\hline \multicolumn{2}{|c|}{$R_{M Z}^{2}$} & 0.15 & 0.28 \\
\hline
\end{tabular}

Extra-binomial distribution of two-level model: $1.009 * *$ 




Figure 1: Voter typology

${ }^{1}$ For clarification purposes we describe the Cue-takers in a very narrow sense of the term, in that the other motivations groups which base their choice on evaluations of the economic situation are not defined as following a cue. We are aware of the danger of excluding reasoning based on perceptions of the economy from the cue-taking process.

${ }^{2}$ Scholars have even argued that personal self-interest, expressed for instance through voters' opinion on their own future economic prospects, outweighs objective indicators of the state of the economy such as unemployment, inflation, interest and exchange rates (Sanders, 1991).

${ }^{3}$ Although several authors have argued that the difference between pocketbook and sociotropic voting is artifactual (Kramer, 1983) and that the pocketbook hypothesis has not been able to gain much hard evidence (Lewis-Beck, 1988; Kinder and 
Kiewiet, 1979), we contend that the affective reactions to the two differ considerably as underlined by Conover and Feldman (1986).

${ }^{4}$ Due to missing data we were able to test only 36 of 38 projects in our model. See the remarks below for further details.

${ }^{5}$ An exception is Marquis (2004). He used the answers for a different purpose, though, namely to relate citizens' answers in the survey to the arguments voiced by political parties and associations in political advertisements in Swiss newspapers.

${ }^{6}$ Kinder and Kiewiet (1981) experienced similar problems when coding open-ended questions in the American NES, e.g. aggregation of issues which do not belong together.

${ }^{7}$ The partitioning of the party family into three categories is most common in research on Swiss voting behavior and in this respect we follow other scholars who use the same categorization (see e.g. Sciarini and Marquis, 2000; Kriesi, 2005).

8 The Swiss Consumer Confidence Survey is comparable to the University of Michigan’s Consumer Sentiment Index. The Swiss survey was first done in 1972.

${ }^{9}$ Measuring the objective state of the economy via the lagged unemployment rate was not possible due to Pearson's correlation of $r=0.494$ with the consumer confidence predictor; for GDP $r=-0.280$ (values significant at the 0.01-level, two-tailed test).

${ }^{10}$ Since the four biggest parties make up the seven-head government in Switzerland, the Federal Council, our variable also measures government support. That is, if the proposal received unanimous support by the political establishment it therefore also receives unanimous government support. Divergences by a member of the Federal Council with his party’s voting recommendation are extremely rare. 